Thorax (1964), 19, 322.

\title{
Solid pulmonary artery
}

\author{
B. GOLDSTEIN AND E. J. JOUBER T ${ }^{1}$ \\ From the Pathology Division, Pneumoconiosis Research Unit, Council for Scientific and Industrial Research, \\ Johannesburg
}

Standard textbooks of pathology do not usually refer to primary malignant tumours of the arteries. They have, however, been described. Elphinstone and Spector (1959) quoted eight cases of solid pulmonary artery resulting from primary sarcomatous growths of the vessel wall, which had been reported since 1924. They also described a case of their own, and subsequently Jacques and Barclay (1960) reported two further cases, a 54year-old woman who had an anaplastic sarcoma, and a 45-year-old man who showed a myxosarcoma of the pulmonary artery. Secondary tumours can also produce a similar effect, and metastatic chondrosarcoma, myxosarcoma, and osteogenic sarcoma have each been found growing as a solid mass in the pulmonary artery (Lowell and Tuhy, 1949 ; Prichard, 1951 ; Laurain, 1957).

The case presented here appears to be the first reported from South Africa, and it also shows certain features not previously noted.

\section{CASE REPORT}

A man aged 51 years was seen for the first time in August 1961 when he gave a history that in November 1958 he had experienced severe left subcostal pain in the anterior axillary line. One week later he experienced a similar pain in the right costal region in the anterior axillary line. A diagnosis of pleurisy was made, and he stayed in bed for six weeks. He was treated with sulphadiazine and antibiotics and was asymptomatic until April 1961 when he again experienced the pain on the left side. The pain was intermittent and became worse on exertion or coughing. It lasted for about a week and since June it had recurred intermittently until the end of August 1961 when the pain eased off considerably. $\mathrm{He}$ had complained of a cough since April 1961, which was particularly worrying in the early morning and was productive of white or yellowish phlegm with occasional specks of bright red blood. He had noticed wheezing in the chest but only on inspiration.

The systematic history revealed nothing of significance. He had smoked an average of 15 cigarettes per day for 30 years but had been a non-smoker for the five months prior to the first examination.

\footnotetext{
1 Thoracic surgeon, Johannesburg
}

CLINICAL FINDINGS On examination he was a thin, $\overrightarrow{0}$ somewhat wasted man. There was no cyanosis bute there was slight clubbing of the fingers. A palpable $e_{N}^{\text {w }}$ lymph node was present in the posterior triangle of $N$ the neck.

Chest A pleural rub was easily audible over the left lower chest posteriorly with diminished air entry.C The right side appeared normal.

Cardiovascular system The pulse rate was 76 beats $\rightarrow$ per minute. The blood pressure was $180 / 110 \mathrm{~mm}$. Hg. The heart sounds were normal but some extrasystoles. ${ }^{+}$ were present. No other abnormalities were detected.

Radiographs Films taken on 16 August showed lobulated mass in the left hilum (Fig. 1).

The patient was admitted to hospital and broncho-o scopy showed the main carina to be central and $\frac{\mathcal{O}}{\mathbb{Q}}$ normal. A small polypoidal growth covered by mucosa was present about $0.25 \mathrm{~cm}$. beyond the carina $\overrightarrow{\hat{O}}$ of the left upper lobe bronchus on its inferior aspect. 3 A biopsy was taken from this growth and bronchial washings were collected from the left upper lobeo bronchus. The palpable node in the left posterior triangle of the neck was not removed because of profuse bleeding, and further anaesthesia was therefore contra-indicated.

OPERATION The approach was made through the bed of the resected left fifth rib. The visceral pleura was $\delta$ thickened and adherent to the parietal pleura in 3 several places. These adhesions were most markedo over the left lower lobe. Several hard masses were palpable in the hilum of the lung.

A radical mediastinal clearance was done. The left pulmonary artery was mobilized and found to contain $N$ a hard mass in its lumen. The pericardium was opened and it was noted that this intra-luminal mass extended $N$ almost as far as the bifurcation of the main pulmonary artery. There was no room to place a ligature, 0 and a Pott's clamp was therefore applied immediately beyond the bifurcation of the main pulmonary artery, and the pulmonary artery was divided just beyond the clamp. The free end of the left pulmonary artery was closed with over and over sutures of 00000 continuous black silk. The pulmonary veins were doubly ligated $\underset{\mathbb{D}}{\stackrel{O}{D}}$ and divided. The left main bronchus was divided just $\stackrel{\square}{\circ}$ beyond the main carina and closed with interrupted $\mathbb{D}$ wire sutures. The left phrenic nerve was divided and the pericardium left widely open.

The chest was closed in standard fashion without 8 underwater drainage. 


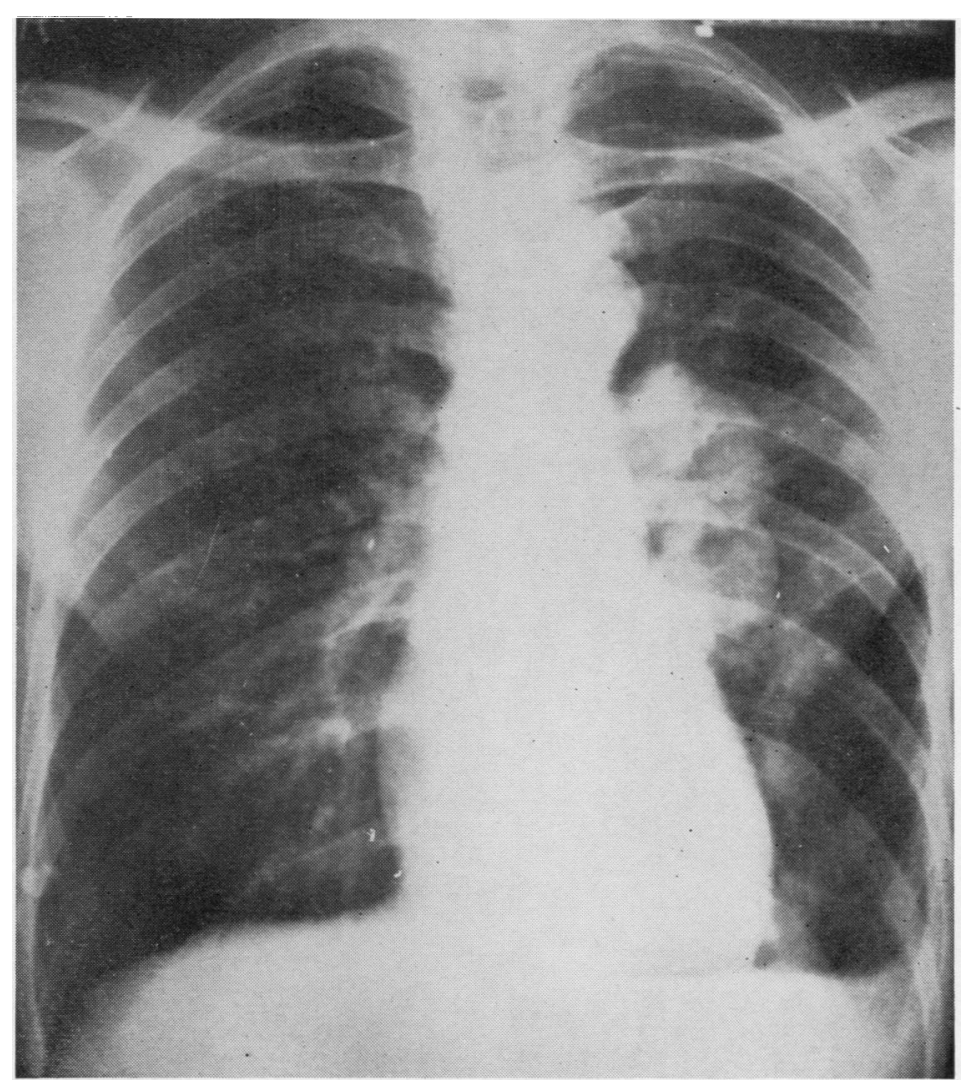

FIG. 1. Chest radiograph.

Bronchoscopy at the end of the procedure revealed some discharge from the right bronchial tree which was aspirated.

POST-OPERATIVE PRogress The right lung was fully expanded on September 13 and the patient's condition was apparently satisfactory.

On September 15 he was somewhat dyspnoeic and the mediastinum was displaced towards the right. Approximately $1800 \mathrm{ml}$. of greyish-pink fluid was aspirated from the left chest. One pint of blood was given intravenously.

On September 17 the patient was very markedly dyspnoeic. Six pints of greyish-pink fluid were aspirated from the left chest. The haemoglobin of the aspirated fluid was $2 \mathrm{~g}$. per $100 \mathrm{ml}$. and a further blood transfusion was given.

The next day he had episodes of severe sweating and hypotension. These attacks came on very suddenly for no apparent reason and terminated as suddenly. An intercostal drain was inserted into the left chest and similar fluid was again removed. Smears made from this fluid showed the features of chyle.

On September 20 the patient's condition was undoubtedly improved and the fluid from the left chest had diminished, but the next day his condition deteriorated rapidly and he died suddenly.

PATHOLOGY The specimen consisted of the left lung and showed that the pulmonary artery and its main branches were occluded by a whitish thrombus which was firm in consistency and was attached to part of the vessel wall (Fig. 2). Examination of the bronchi revealed a fragment of necrotic material in the main upper lobe bronchus, and the mucosa of the inferior lingular bronchus showed an area of thickening and irregularity, approximately $1.5 \mathrm{~cm}$. from its origin, related to an underlying necrotic tumour mass which appeared to be filling a branch of the pulmonary artery and eroding through the vessel wall. On crosssection of the lung the branches of the pulmonary artery could be seen to be occluded by solid greyishwhite material which was partly adherent to the vessel wall (Fig. 3). An infarct of approximately $3 \times 4 \mathrm{~cm}$. in size was present in the lateral basal segment of the lower lobe.

Sections from the inferior lingular bronchus showed the presence of neoplastic tissue, most of which was situated deep to the cartilage, but a fragment had encroached onto and replaced the mucosa (Fig. 4). 


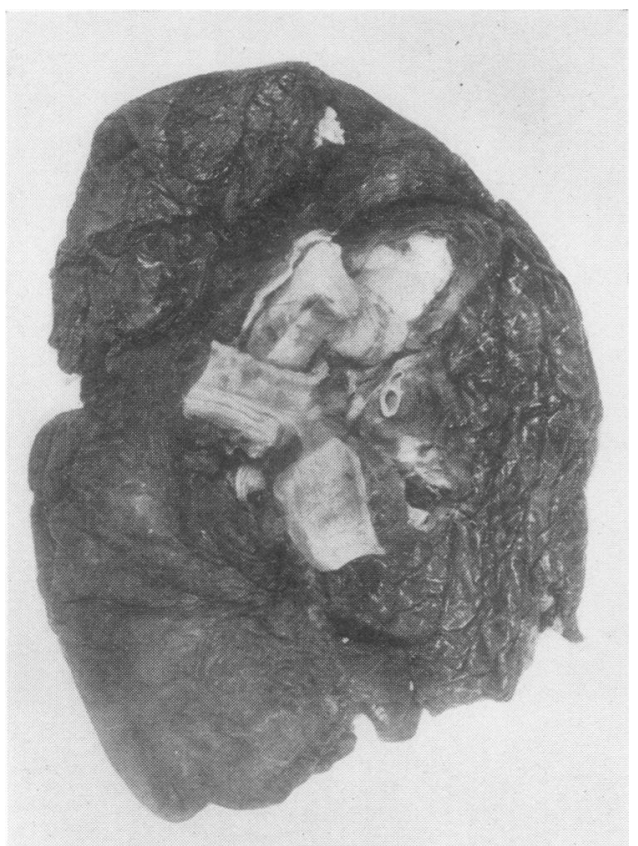

FIG. 2

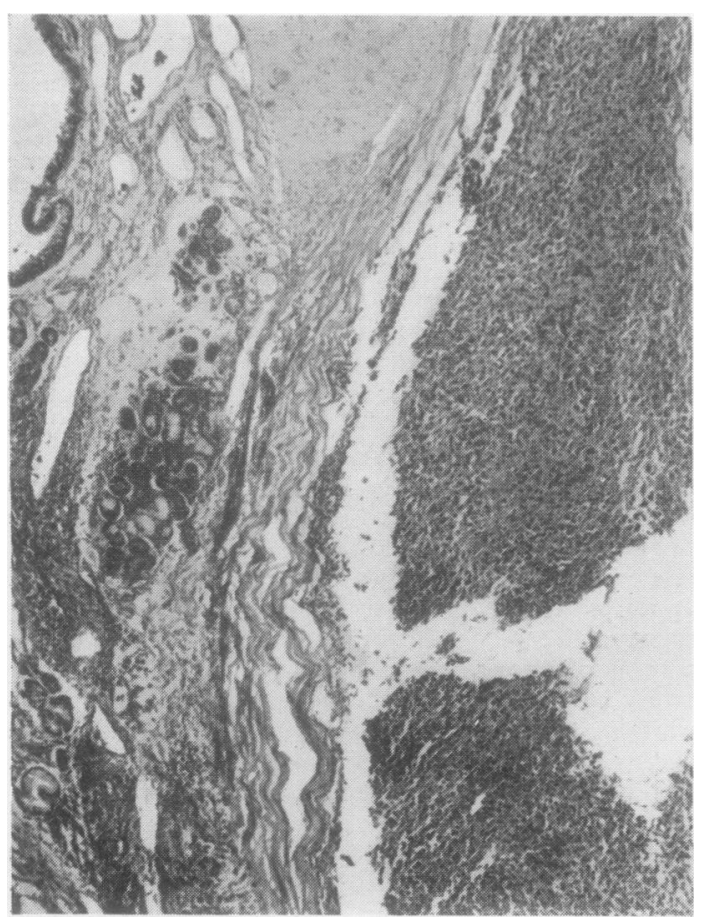

FIG. 4

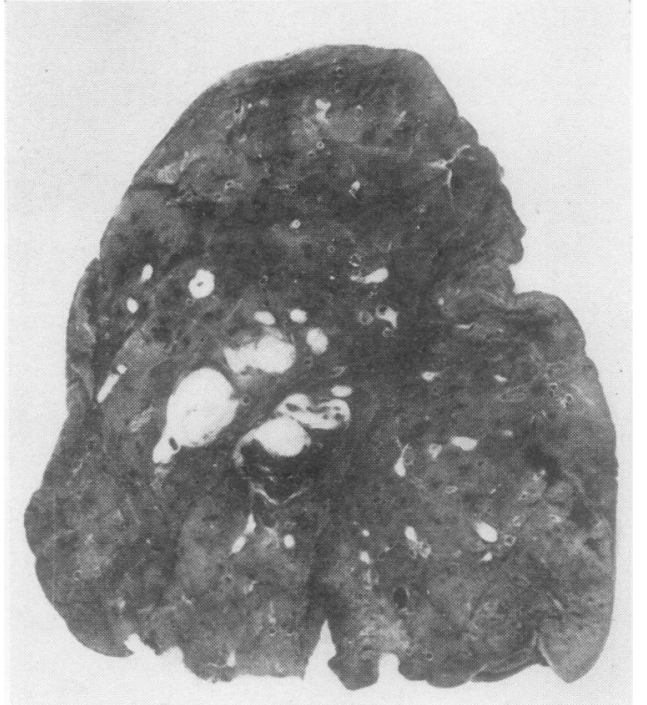

FIG. 3

FIG. 2. The pulmonary artery occluded by thrombus.

FIG. 3. Thromhus in the branches of the pulmonary artery and the necrotic mass in relation to the bronchus.

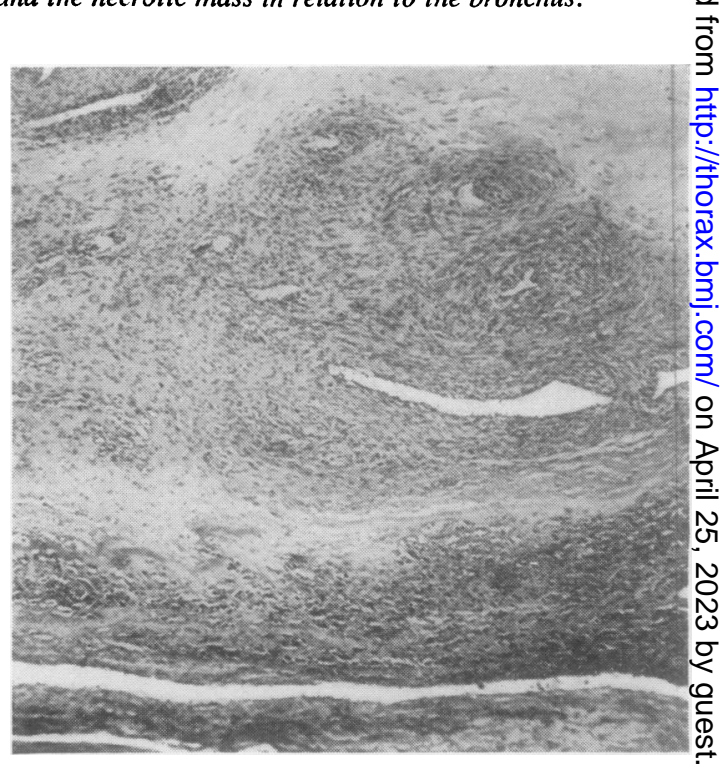

FIG. 4. Section of the inferior lingular bronchus showing $\frac{T_{\overrightarrow{0}}^{\circ}}{\mathrm{T}}$ tumour growth on the mucosal surface. Haematoxylin ando eosin, $\times 15$.

FIG. 5. Section of the pulmonary artery showing rumouk cells growing in the thrombus. Haematoxylin and eosin, $?$ $\times 15$. 


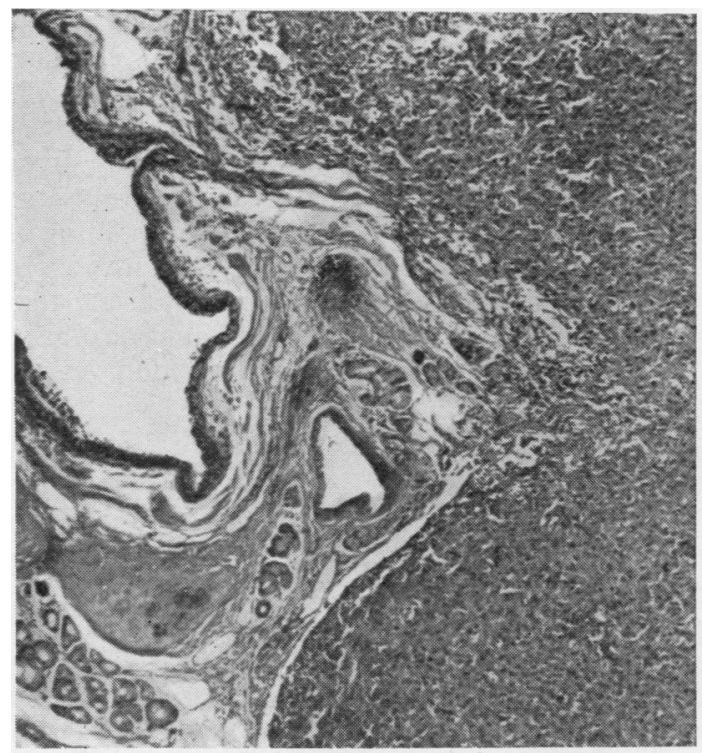

FIG. 6

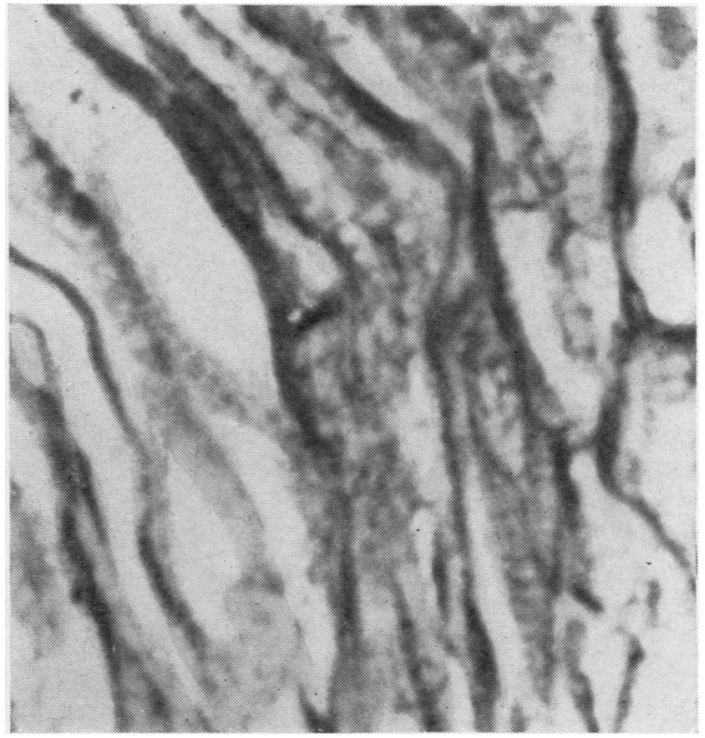

FIG. 8

FIG. 6. Section of the tumour in the pulmonary artery extending close to the bronchial mucosa. Haematoxylin and eosin, $\times 15$.

FIG. 8. Section of the tumour showing spindle cells with cross-striations. Phosphotungstic acid haematoxylin, $\times 240$.

A section from the pulmonary artery near the line of surgical excision showed the presence of organized thrombus with superadded recent thrombus and neoplastic tissue growing in the thrombus, particularly around the canalizing blood vessels (Fig. 5).

A section from the pulmonary artery at the site of the necrotic mass showed extensive neoplastic tissue filling the artery and extending very close to the bronchial mucosa (Fig. 6). Although serial sections were cut, a definite site of communication could not be demonstrated.

In all these sections the tumour consisted of large pleomorphic cells showing vesicular and hyperchromatic nuclei and indistinct cell boundaries. The cells were round, oval, elongated, and pear-shaped, and many were multinucleated. Giant cells were also present (Fig. 7). There was a variable amount of stroma, and special staining revealed reticulin fibres enclosing groups of cells. Staining with phosphotungstic acid haematoxylin for myofibrils produced conflicting results; in the original biopsy, myofibrils were not seen, and on this basis a diagnosis of undifferentiated large cell bronchogenic carcinoma was suggested. In the subsequent sections myofibrils were demonstrated, and in a few cells cross-striations were observed, indicating that the tumour was in fact a rhabdomyosarcoma (Fig. 8). This diagnosis has also been accepted by the Soft Tissue Tumour Panel of the Armed Forces Institute of Pathology, Washington, D.C.

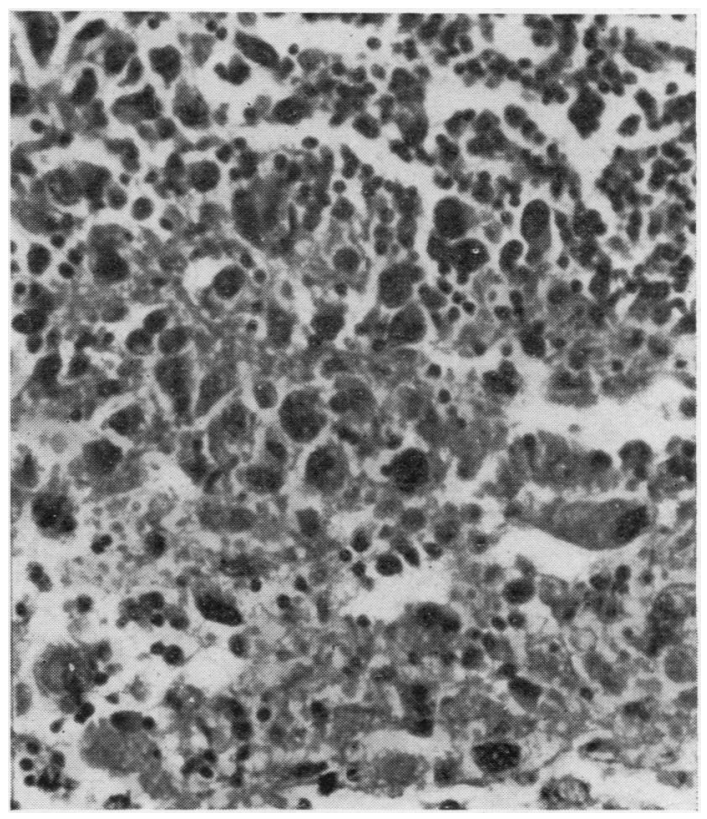

FIG. 7. Section of the tumour showing pleomorphism, pear-shaped cells, and giant cells. Huematoxylin and eosin, $\times 96$. 


\section{DISCUSSION}

This case shows two features not previously reported. First, there is definite evidence that the tumour involving the pulmonary artery wall is a rhabdomyosarcoma. Some of the previous cases reported may have been of a similar nature, but as no mention is made of special staining of histological sections, no definite conclusions can be drawn. Thus, for instance, Kudlich and Schuh (1934) described their case as a 'myoplastic sarcoma with giant cells', while Goedel's (1935) case showed a spindle-celled tumour in which there were large cells with hyperchromatic nuclei and also band-like cells.

The second feature is that the tumour appears to have eroded into a bronchus. Rhabdomyosarcomata occur in sites where muscle is present, even though there is only smooth muscle. As a result of the tumour of the arterial wall a thrombus occurred at this site, became organized, and was enlarged by the formation of fresh thrombus, while the tumour continued to grow in the thrombus. Subsequently it eroded through the vessel wall and penetrated the adjacent bronchus.

That the tumour arose initially from the bronchus cannot entirely be excluded. Primary leiomyosarcomata of the bronchus have been reported; Randall and Blades (1946) quote six previous cases and describe a case of their own. It is stated (Elphinstone and Spector, 1959), however, that malignant tumours rarely invade the media of an artery from the outside. Clinically, there was no evidence of any other site of origin, but this could only have been established definitely at necropsy, which was refused.
Primary rhabdomyosarcomata of the lung also occur, but the origin of the striated muscle fibres? has been debated. Spencer (1962) quoted the음 various theories: that they arise from undifferentiated mesoblastic cells; that they develop from misplaced voluntary muscle tissue from thes pharyngeal region; that they represent a form of intrapulmonary teratoma ; or that they arise from: the pleura. The case described may indicate that $\vec{\omega}$ rhabdomyosarcomata of the lung could also arise from the muscle component of the blood vessels, $\overrightarrow{\vec{x}}$ the bronchial tree, or the lymphatics.

\section{SUMMARY}

A case of solid pulmonary artery due to a neo-근 plasm of the arterial wall is described, and refer- $\vec{c}$ ence is made to 11 previously reported cases. The histological pattern of these cases had not been clearly established, but the present case was showno to be a rhabdomyosarcoma.

\section{REFERENCES}

Elphinstone, R. H., and Spector, R. G. (1959). Sarcoma of the pulO monary artery. Thorax, 14, 333

Goedel, A. (1935). Zur Kenntnis des primären Lungenschlagader Sarkoms. Frankfurt. Z. Path., 49, 1

Jacques, J. E., and Barclay, R. (1960). The solid sarcomatous pul monary artery. Brit. J. Dis. Chest, 54, 217.

Kudlich, H., and Schuh, W. (1934). Ein Beitrag zum myoplastischer Sarkom der Lungenschlagader. Virchows Arch. path. Anat., 294. Sarkom der Lungenschlagader. Virchows Arch. path. Anat., 294, 113

Laurain, A. R. (1957). Intracardial tumor culture of osteogenic sarcoma with fatal tumor embolism. Report of a case. Amer. $J$. clin. Path., 27, 664 .

Lowell, L. M., and Tuhy, J. E. (1949). Primary chondrosarcoma of the lung. J. thorac. Surg., 18, 476

Prichard, R. W. (1951). Tumors of the heart. Review of the subjection and report of one hundred and fifty cases. A.M.A.Arch. Path. and report of one hundred and fifty cases. A.M.A. Arch. Path.?

$\mathbf{5 1}, 98$

Randall, W. S., and Blades, B. (1946). Primary bronchiogenic leio 3 myosarcoma. Ibid., 42, 543.
. Spencer, H.(1962). Pathology of the Lung, p. 723. Pergamon, London? 